\title{
O trabalho de atendentes em atividades administrativas de um serviço ambulatorial: o serviço e as relações com pacientes e médicos
}

\author{
Administrative duties of ambulatory attendants: \\ their job and relationships with patients and doctors
}

\author{
Ivan Bolis' \\ Laerte Idal Sznelwar ${ }^{1}$ \\ Márcia Terra da Silva ${ }^{1}$
}

\begin{abstract}
Resumo: A abordagem organizacional fornece uma visão ampla das situações de trabalho, o que permite a melhoria dos processos e a construção de situações de bem-estar para os trabalhadores. Devido à natureza do serviço oferecido, que implica a presença de diferentes categorias de clientes, em algumas atividades podem ocorrer situações de conflito, como no caso de atendentes em atividades administrativas de um serviço ambulatorial. Eles exercem atividades nas quais são os conectores entre os pacientes e os médicos, dois tipos de clientes com diferentes e, às vezes, contrastantes necessidades. Análises sobre as características do serviço, como perecibilidade, intangibilidade e coprodução, permitiram encontrar elementos que provocam problemas e, como consequência, podem causar uma situação difícil para os atendentes. Esse fato poderia ser considerado normal para tal tipo de serviço, todavia, pode ser uma fonte de problemas de produção e de saúde para esses trabalhadores. Desse modo, consideramos ser importante propor mudanças organizacionais, visando melhorias neste tipo de situação de trabalho.
\end{abstract}

Palavras-chave: Serviços. Ergonomia. Administração Hospitalar.

\begin{abstract}
An organizational approach can provide a wider range of work situations thus enabling improvements in the processes providing wellbeing of workers. In some activities, due to the nature of the service offered, which implies the presence of different types of customer, some conflict situations can occur. This is the case of attendants carrying out administrative duties of ambulatory services. They sometimes act as the link between the patients and the doctors, two different types of customers with different and sometimes contrasting needs. The analysis of service features such as intangibility, perishability, and co-production enabled to identify elements that cause problems and consequently difficult situations in the workplace. This could be considered normal considering this kind of service; however, it can affect production and lead to health problems for these workers. Therefore, it is important to propose organizational changes seeking improvements in this type of work situation.
\end{abstract}

Keywords: Services. Ergonomics. Hospital administration.

\section{Introdução - Projeto ergonômico num Hospital Universitário (HU)}

A composição deste artigo foi efetuada com base em um projeto de ação ergonômica desenvolvido em um Hospital Universitário; tal análise focaliza o estudo do Serviço de Atendimento administrativo aos clientes, na área do Ambulatório.

Nessa área foi destacada a presença de muitas queixas por parte dos atendentes, associadas a problemas de saúde no trabalho. Em 2006, foi realizada uma intervenção de tipo ergonômico (BOLIS, 2011), tendo sido desenvolvida uma "Análise Ergonômica do Trabalho" - AET (GUÉRIN et al., 2001), o que permitiu diagnosticar os principais problemas enfrentados pelos trabalhadores neste atendimento.

A esta abordagem foi agregada uma análise organizacional e a temática de serviço foi ressaltada. Foram, então, identificadas questões intrínsecas ao desenho do trabalho dos atendentes que melhor explicam a situação encontrada anteriormente. Por exemplo, no Serviço de Atendimento administrativo no Ambulatório, o atendente exerce uma atividade de elo entre dois sujeitos: os profissionais médicos e os pacientes. Esta posição pode ser fonte de sofrimento psíquico, pois os trabalhadores que estão

\footnotetext{
${ }^{1}$ Departamento de Engenharia de Produção, Escola Politécnica, Universidade de São Paulo - USP, Av. Professor Almeida Prado, Travessa 2, 128, Cidade Universitária, CEP 05508-070, São Paulo, SP, e-mail: bolis.ivan@yahoo.it
} 
em contato com os clientes desenvolvem um papel de fronteira, agindo entre várias expectativas, muitas vezes conflitantes, e que provocam, no trabalhador, um impacto significativo sobre seu comportamento e suas atitudes (WEATHERLY; TANSIK, 1993).

Partindo da análise da AET e nos aprofundando na temática da gestão de serviços, o objetivo deste artigo é verificar se a análise acurada do conceito do Serviço de Atendimento no Ambulatório do hospital estudado nos permite entender melhor as condicionantes. Dessa forma, o artigo possibilita refletir sobre o entrosamento de metodologias e técnicas oriundas de abordagens distintas e sua capacidade de se complementarem ou de validarem as conclusões. Destacamos o estudo das relações entre o Serviço de Atendimento administrativo e os médicos e os clientes, que desencadeiam pressões sobre os atendentes, além de verificar se o estudo detalhado do serviço pode ajudar a organização a projetar serviços que sejam mais eficientes e eficazes, minimizando as pressões sobre alguns dos atores presentes no sistema.

\section{Revisão bibliográfica}

\subsection{Análise Ergonômica do Trabalho}

A Análise Ergonômica do Trabalho (AET) é reconhecida no âmbito universitário como uma das principais abordagens da Ergonomia, caracterizada pela proposta de analisar as atividades dos sujeitos nas situações de trabalho, com o objetivo de adaptar o trabalho ao ser humano (ABRAHÃO et al., 2009).

Um de seus conceitos fundamentais é a distinção entre o conceito de tarefa e de atividade, pois:

A tarefa é o que se deve fazer, o que é prescrito pela organização. A atividade é o que é feito, o que o sujeito mobiliza para efetuar a tarefa. (FALZON, 2007, p.9).

A AET é centrada na análise das atividades em situações reais de trabalho e pode ser definida como um modelo metodológico de intervenção e transformação que permite levantar a complexidade presente nas relações entre trabalho e homem, sem se basear em estudos por meio de modelos desenvolvidos anteriormente (WISNER, 2004).

Em situações reais de trabalho, os sujeitos elaboram estratégias originais para atender às tarefas prescritas pelas organizações e, por essa razão, não é possível estudar as consequências das atividades sobre a saúde por meio de simples estudos de fatores de risco. Para fazer isso é necessário ter conhecimento do papel ativo do trabalhador para, num segundo momento, com a sua participação efetiva, conseguir formular os modelos operatórios mais favoráveis para a saúde (GUÉRIN et al., 2001).
Com o objetivo de trazer a questão do trabalho para níveis estratégicos de decisão, nossa proposta é realizar uma discussão na qual a ergonomia possa ser enriquecida pelos conceitos de organização do trabalho em serviços.

\subsection{Definições de serviço}

$\mathrm{Na}$ literatura, podem ser encontradas várias definições de serviço, sobretudo quando consideramos a crescente importância, na economia mundial, do emprego terciário (GADREY, 2001). Entre as diferentes linhas conceituais, podem ser destacadas duas abordagens principais:

- A primeira, define o serviço partindo de estudos voltados à organização de trabalho, distinguindo entre a "lógica neofordista" e a "lógica de serviço".

[...] [a lógica de serviço não se refere ao] setor de serviços em si, mas da intensidade das relações e interações entre os atores da oferta e da demanda, atores esses que cooperariam em diversos graus para a obtenção de serviços e de efeitos úteis. Genericamente, relações de serviço poderiam ser concretizadas como modalidades de interconexão entre os prestadores de serviço e os clientes a propósito da resolução do problema pelo qual o cliente se dirige ao prestador [...] (SALERNO, 2001, p. 17).

Nesse caso, a produção de serviço é entendida como um processo de transformação nas condições de atividade dos usuários.

- A segunda abordagem, por sua vez, efetua uma comparação distintiva entre o conceito de produto (manufatura) e o de serviço (GRONROOS, 1994; GIANESI, 1994; CAON; CORRÊA, 2002). Normann (1993) introduz o conceito de serviço como:

Este constitui os benefícios oferecidos para o cliente. Como podemos ver, o conceito do serviço consiste frequentemente em um conjunto muito complexo de valores que são muitas vezes difíceis de analisar. Alguns dos benefícios são físicos e outros psicológicos ou emocionais; além disso, alguns são mais importantes e podem ser chamados serviço-núcleo, enquanto outros são de caráter mais periférico; algumas características podem ser mensuradas e especificadas, enquanto outras podem ser de importância extrema embora de especificações quase impossíveis. (p. 65)

Entender as características do serviço permite analisar e conhecer os impactos sobre o trabalho com o objetivo de ajudar a empresa na busca de melhorias e para atingir os seus objetivos. Conhecer 
suas características permite levantar os pontos críticos presentes na operação para que a empresa consiga superá-los.

Com base na segunda abordagem, Bowen e Ford (2002) analisam a administração de operações a partir das características que, classicamente, são relacionadas à produção de serviço:

- Intangibilidade: a avaliação da qualidade, eficácia e eficiência nos produtos intangíveis depende da percepção do cliente, o que a torna subjetiva. Se não há resultado para se mostrar, comparar ou testar objetivamente, as empresas precisam buscar junto aos clientes os principais indicadores de avaliação. Esta aferição da qualidade vai interferir na relação entre trabalhador e cliente, na qual o segundo avalia, por meio da própria percepção, o trabalho do primeiro (SILVA; TAVARES, 1998);

- Coprodução: para os processos de serviço que se realizam sobre o cliente ou com a sua ajuda, qualquer falha deve ser resolvida pelos trabalhadores de contato em conjunto com o cliente, enquanto o serviço está sendo consumido. Esses trabalhadores precisam ser, portanto, bons negociadores e ter habilidades para solucionar os problemas de modo aceitável pelo cliente, que define, por sua vez, a qualidade baseado em suas próprias percepções. Em resumo, esses trabalhadores não só produzem o serviço em cooperação com outros atores, mas precisam, também, estar prontos para resolver os problemas. Serviços bem sucedidos precisam incluir os clientes como potenciais coautores e, para isso, os trabalhadores precisam desenvolver habilidades, motivação e, além da necessidade da possibilidade de aprendizagem contínua. $\mathrm{O}$ cliente em serviço, muitas vezes, desorganiza as relações prescritivas tradicionais, fazendo com que a ação conjunta do cliente com o trabalhador coloque em evidência a questão da subjetividade na relação de trabalho, e seja necessária uma comunicação efetiva para produzir solução aceitável pelo cliente e pelo trabalhador, dentro dos padrões da organização (HUBAULT, 2001);

- Perecibilidade: a impossibilidade de estocar a relação com o cliente é outro fator importante para entender as dificuldades de gerenciar a coprodução de serviços. Não é possível entregar um serviço quando a demanda excede a capacidade, portanto, conseguir gerenciar a demanda é estratégico para um serviço, visto que a demanda é muito sensível ao tempo. Ela pode ser gerenciada, por exemplo, fazendo agendamentos ou introduzindo atrativos para a compra nos momentos de vale (yield management - preço cobrado nos momentos de vale diferente do momento de pico). A oferta do serviço também precisa ser gerenciada para otimizar os recursos da organização e permitir melhor qualidade na prestação do serviço. As falhas no gerenciamento da demanda ou da oferta causam consequências negativas diretas, sobretudo, para os trabalhadores que estão em contato com os clientes; e

- Heterogeneidade: a demanda, os resultados e o processo de um serviço são diferentes entre clientes, devido às diferenças de cada um, não apenas no que diz respeito às necessidades, como também em relação às características dos sujeitos: cada atendimento é uma relação que se cria e se desenvolve. Por isso as empresas têm dificuldade em encontrar indicadores objetivos para avaliar os resultados, considerando a heterogeneidade relativa às expectativas de cada cliente. Os trabalhadores em serviços têm que desenvolver suas atividades, lidando com a heterogeneidade dos clientes.

A heterogeneidade faz com que cada ator presente no sistema tenha diferentes pontos de vista com relação à avaliação do mesmo serviço. Em virtude disso, Bowen e Ford (2002) afirmam que avaliar a qualidade de um serviço é bem mais complicado do que avaliar a qualidade de um produto. Para avaliar a qualidade de um serviço, Gadrey (2001) afirma que a empresa tem que considerar não só um indicador, mas precisa planejar o serviço de modo a conseguir o melhor trade-off entre vários e diferentes índices. Com um diferente olhar, Zeithaml et al. (1990) também enfatizam que, pela sua natureza, a avaliação do serviço é difícil de ser feita quantitativamente.

A qualidade do serviço é definida como a diferença entre a percepção do serviço prestado e o serviço esperado pelo cliente e esta avaliação é subjetiva devido às características de intangibilidade. Portanto, são os clientes que avaliam o resultado, o processo e a qualidade, não em termos daquilo que objetivamente recebem, mas em termos da percepção que têm em relação ao esperado. É difícil para as empresas prever a qualidade, porque quem a define é o cliente (HESKETT; SASSER; HART, 1994).

Em relação a "pacotes de serviço", o esperado pelo cliente também pode não considerar o que um serviço específico realmente pode entregar. É possível afirmar que este serviço seja avaliado partindo dos resultados ou das características de outro, o que poderia provocar, nos trabalhadores do primeiro serviço, frustração, em ver a avaliação do seu trabalho influenciada por fatores não dependentes deles, além 
de provocar desmotivação diante de dificuldades para dar bom andamento às queixas dos clientes.

Considerando a produção do serviço e a necessidade de se compreender os elementos que participam na definição e na construção dele (como a presença de diferentes "atores"), no próximo item, focalizamos o conceito de encontro de serviço, baseando-nos nas lógicas ou racionalidades de serviço.

\subsection{Lógicas ou racionalidades de Serviço}

Kingman-Brundage, George e Bowen (1995) introduzem o conceito de que prestar um serviço é agir num sistema integrado, no qual várias racionalidades coexistem. Apenas quando a empresa entende a experiência de serviço dos empregados e dos clientes ela consegue controlar e gerenciar o serviço, possibilitando uma ligação eficaz entre os processos-chave. A crescente importância de se focalizar nos clientes está presente em todas as indústrias, mas principalmente em serviços nos quais as empresas são desafiadas, de modo mais evidente, a satisfazer seus desejos.

A coprodução implica que o processo de produção seja avaliado pelo cliente, assim como os resultados, isto é, não basta atingir os resultados do serviço, mas sim avaliar o processo pelo qual tais resultados foram obtidos, que deve ser coerente com os objetivos iniciais especificados, e, desse modo, é necessária uma racionalidade integrada e colaborativa entre os atores envolvidos.
Com o intuito de explicar a presença e a necessidade de alinhar diferentes racionalidades, KingmanBrundage, George e Bowen (1995, p.24) introduziram o seguinte modelo teórico (Figura 1) que identifica os fatores essenciais para serem considerados na prestação de um serviço e as suas respectivas interações.

As principais racionalidades são influenciadas e dirigidas por meio de alguns parâmetros, tal qual como a definição do conceito do serviço, ou seja, o que a empresa está preparada para oferecer, partindo do que os clientes precisam, e as suas propostas enquanto organização.

Essas são, em parte, moduladas pelo que se conhece como "cultura organizacional", fruto de um conjunto de valores e normas que norteiam a organização da produção e do trabalho, os conteúdos das tarefas e, também, a busca por educar os clientes com relação às propostas de prestação de serviços.

O objetivo da empresa que almeja produzir um serviço de qualidade é alinhar as três racionalidades e, sucessivamente, permitir que os conflitos nas interfaces sejam conhecidos e resolvidos.

O modelo apresenta as três racionalidades:

- A do cliente: representa a visão do cliente sobre o processo e a entrega do serviço, além de representar o grupo de fatores que o influenciam no ato de utilização do serviço;

- A técnica: representa todo o conhecimento técnico da organização, é o grupo de fatores e processos que caracterizam a rotina de atuação

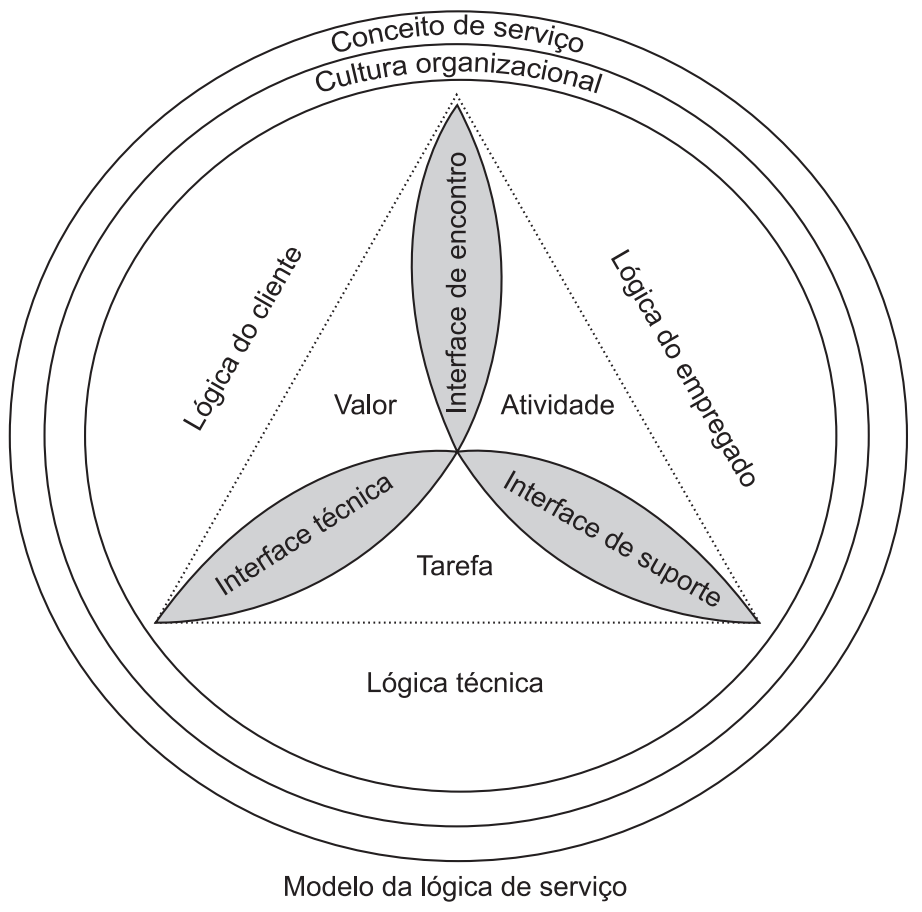

Figura 1. Modelo da lógica (racionalidade) de serviço - adaptado de Kingman-Brundage, George e Bowen (1995). 
da instituição e permitem compreender o que ocorre nas situações de prestação do serviço e seus efeitos sobre a sua eficácia e qualidade; e

- A do empregado: representa o papel do empregado e a sua visão sobre o próprio trabalho e os aspectos do serviço. É identificado como o grupo de fatores que caracteriza a atividade usual do atendente, que orienta as próprias ações com o intuito de responder adequadamente às necessidades dos usuários e às prescrições da instituição, além de possibilitar a resolução de eventuais problemas com seu conhecimento.

Há na literatura outros modelos teóricos mais específicos do Serviço de Atendimento administrativo (FERREIRA, 1999), que focalizam a atenção sobre a importância dos trabalhadores da linha de frente que estão em contato direto com os clientes e têm importância capital para o desenvolvimento do processo do serviço. Nos encontros de serviço, se dão os momentos em que os clientes interagem diretamente com as organizações (SHOSTACK, 1985), nos quais o cliente observa a qualidade do desempenho da empresa (BITNER, 1995). Em geral, a qualidade das interações pessoais entre clientes e atendentes tem papel fundamental na percepção de como a empresa será avaliada (HARTLINE; JONES, 1996).

No primeiro contato com o cliente, ocorre o "momento da verdade" (NORMANN, 1993) ou "hora da verdade" (CARLZON, 1994), pois é o momento no qual o cliente entra em contato com a organização, analisa se a sua necessidade foi bem encaminhada e inicia o julgamento do serviço.

Estudos sobre a percepção da qualidade do serviço indicam como os clientes, partindo da própria experiência e dos elementos visíveis, percebem a qualidade do serviço de toda a organização com base na sua experiência no ato de atendimento e no contato com as pessoas da linha da frente (GRONROOS, 1984).

Buscando demonstrar esta relação, uma pesquisa (SEBRAE, 1995) mostrou que, em $70 \%$ dos casos, as razões para as empresas mudarem de fornecedor não eram em virtude da qualidade do serviço/ produto em si, mas sim devido à má qualidade de atendimento;

Considerando a importância do Serviço de Atendimento, pode-se entender o importante papel de mediadores feito pelos trabalhadores da linha de frente, visto que atender ao cliente é também gerenciar contatos pessoais e ser o intermediário entre a racionalidade técnica da empresa e as necessidades dos clientes, evidenciando os conflitos potenciais ou já existentes. Esta consideração é importante, pois justifica a necessidade de se estudar o trabalho dos atendentes no que diz respeito aos aspectos físicos, cognitivos e psíquicos de sua atividade.
Segundo Dejours (2004, p. 65), o conceito de trabalho pode ser definido como "[...] a atividade manifestada por homens e mulheres para realizar o que ainda não está prescrito pela organização do trabalho".

A mobilização da subjetividade está presente em qualquer atividade e é ainda mais necessária para enfrentar a imprevisibilidade, presente em muitas situações de trabalho em serviços. Trata-se de uma das características humanas, a capacidade criativa, não existente no sistema técnico-maquinal, não sendo, portanto, passível de prescrição, uma vez que seria parte do zelo dos trabalhadores para realizar o necessário para desenvolver um trabalho útil e belo (DEJOURS, 2008). Apesar de ser central nos sistemas de produção, o trabalho humano é:

[...] extremamente frágil: depende da dinâmica entre contribuição e retribuição. Em contrapartida à contribuição que leva à organização do trabalho, o indivíduo espera ser retribuído [...] (DEJOURS, 2004, p.71)

desse modo, o trabalho precisa ser reconhecido, caso contrário, a tendência é a desmobilização subjetiva. Esta retribuição tem muito de simbólica, o reconhecimento não se dá apenas na esfera material.

$\mathrm{Na}$ presença de um serviço de linha de frente, o funcionário se envolve com os clientes, neste sentido, toda atividade, em especial aquelas que colocam as pessoas em interação com outras, mobiliza psiquicamente uma forte relação intersubjetiva. Situações críticas para o trabalhador, como quando ele não tem condições para lidar com as necessidades e exigências dos clientes, tendo em face também os imperativos da organização, são significativamente anxiogênicas.

Há empresas que, considerando a importância deste aspecto, propõem uma gestão dos aspectos subjetivos do trabalho. Existem casos em que propõem um "serviço emocional", utilizando a emoção para aumentar o valor do serviço, por exemplo, pela prescrição do sorriso para obter maior controle sobre as reações dos trabalhadores (HOCHSCHILD, 1983; VAN MAANEN, 1991).

Mesmo em situações não críticas é requerido que os trabalhadores consigam lidar com as próprias emoções nas relações sociais, o que pode ser causa de sofrimento patogênico para os trabalhadores, pois se exige que eles se encaixem na "lógica técnica", isto é, que se enquadrem em um nível de prescrição no qual o aspecto emocional seria controlado de maneira heterônoma. Isto é muito grave no que diz respeito à economia psíquica, são situações nas quais o trabalhador se veria obrigado a agir de modo contrário aos seus princípios e valores. Neste tipo de cenário de produção, prevalece o sofrimento patogênico, que pode ser ainda mais grave quando a 
avaliação do próprio serviço prestado é feita a partir de indicadores que não podem ser influenciados pelos trabalhadores, motivando afastamentos do trabalho por distúrbios de ordem psíquica bastante prevalentes nestas situações.

\subsection{Metodologia utilizada}

Neste artigo, são apresentados aspectos da produção e do trabalho no Serviço de Atendimento ambulatorial. Para o levantamento de dados, foram realizadas entrevistas com gestores baseadas em abordagens da gestão de operações em serviços. Com relação ao trabalho, foi feita uma análise inspirada na ergonomia da atividade (Análise Ergonômica do Trabalho) focada no levantamento das características do processo, das prescrições, de observações gerais da atividade e de verbalizações de trabalhadores. Com relação à avaliação da qualidade do serviço, foi feito um levantamento de expectativas, junto aos usuários, baseado na metodologia QPS.

\subsection{Sobre a tarefa e a atividade}

A ergonomia utiliza métodos e técnicas científicas para observar o trabalho humano com o objetivo de apreender a complexidade do trabalho, de decompor as atividades em indicadores observáveis, como a postura, as ações, a comunicação, a exploração visual e o deslocamento. A partir dos resultados iniciais, obtidos e validados com os funcionários, chega-se a uma síntese que permite a explicação da inter-relação de vários fatores condicionados à situação de trabalho. Como em todos os processos científicos de investigação, a espinha dorsal de uma intervenção ergonômica é a formulação de hipóteses.

A organização das observações em uma situação real de trabalho é feita com relação a hipóteses que guiam a análise, mas também, considerando as imposições práticas e as facilidades de cada situação de trabalho (GUÉRIN et al., 2001).

As técnicas utilizadas em Ergonomia podem se agrupar em técnicas objetivas e técnicas subjetivas (CHAPANIS, 1997):

- Técnicas objetivas ou diretas: são constituídas de técnicas que impõem uma etapa importante no tratamento dos dados, consistem no registro das atividades durante um longo período, como um registro em vídeo;

- Técnicas subjetivas ou indiretas: técnicas que tratam do discurso do trabalhador, constituídas de questionários e entrevistas. Deve-se considerar, ainda, que essas técnicas são aplicadas segundo um plano preestabelecido de intervenção em campo, com um dimensionamento da amostra a ser considerado em função dos problemas abordados.

As principais ferramentas utilizadas nesta pesquisa foram observações abertas, verbalizações dos atendentes e entrevistas estruturadas com os responsáveis pela execução do serviço. A primeira representa a metodologia mais utilizada pelos profissionais da área de ergonomia na medida em que permite entender globalmente os aspectos envolvidos na realização de uma atividade de trabalho. A segunda, as entrevistas e verbalizações, considera que o discurso do operador (atendente) é muito importante para ser analisado porque contém dados relevantes. Conforme Montmollin (1984), esta é a expressão direta dos processos cognitivos que o trabalhador utiliza para a execução e a realização de uma tarefa. Para o presente artigo, este tipo de entrevista foi desenvolvido simultaneamente à realização das tarefas de trabalho dos operadores. Como última ferramenta, as entrevistas estruturadas podem levar o pesquisador a entender e levantar diretamente as informações sobre aspectos bem definidos.

\subsection{Sobre a percepção da qualidade do serviço}

Utilizada principalmente na área da logística (RUGGERI, 1999), a metodologia QPS (qualità percepita del servizio - qualidade perceptível do serviço) ajuda na avaliação da qualidade do serviço percebido do cliente. A metodologia se desenvolve segundo as seguintes fases: classificação dos clientes em grupos homogêneos, individuação dos indicadores esternos de serviço (KPI - Key Performance Indicators - indicadores-chave de desempenho) relevantes para o cluster de clientes, elaboração e subministração do questionário preliminar a um grupo de clientes representativo, análise das respostas e elaboração do questionário definitivo, subministração ao universo pesquisado, análise das respostas e atribuição de valores numéricos por avaliação e dos pesos aos indicadores. Há diferentes maneiras de chegar ao indicador de QPS, dependendo das necessidades do avaliador.

No caso em análise, a atribuição de valores numéricos por avaliação VIEi será feita atribuindo valores com critério a "passo constante", ou seja, numa escada linear.

Os pesos Pij sobre cada KPI i-ésimo e sobre cada cliente j-ésimo será calculado segundo a seguinte formula matemática (Equações 1 e 2):

$$
P i j=\frac{I+1-O i j}{\frac{I(I+1)}{2}}
$$




$$
\sum_{i=1}^{I} P i j=1
$$

Com: $\mathrm{I}=$ Número de KPI $=8$.

Oij = Ordem de importância atribuído do cliente j-ésimo ao KPI i-ésimo.

A fórmula da qualidade percebida do serviço é (Equações 3 e 4)::

$$
Q P S=\sum_{i=1}^{I} V I E i * P I E i
$$

com:

$$
P I E i=\frac{\sum_{j=1}^{J} P i j}{J}
$$

VIEi = Média numérica atribuída à avaliação expressa dos clientes relativa ao KPI i-ésimo.

PIEi = Média dos pesos atribuídos ao KPI i-ésimo, baseando-se na importância indicada dos clientes.

\section{Resultados}

\subsection{Serviço de Arquivo Médico e Estatística (SAME)}

O Serviço de Arquivo Médico e Estatística (SAME) presta serviços para o serviço de consultas médicas, para o pronto atendimento e para as diferentes enfermarias.

O Serviço de Atendimento administrativo ambulatorial é um dos três serviços do SAME. Os principais objetivos a serem cumpridos em tal serviço são: a recepção dos usuários que chegam às consultas médicas ambulatoriais, dar apoio administrativo aos médicos, aos enfermeiros e a outros profissionais da equipe de saúde, além de permitir o levantamento dos dados de pacientes por meio dos prontuários a partir dos quais é possível ter acesso às histórias clínicas. Em tal serviço trabalham 29 pessoas, divididas entre 21 mulheres e 8 homens, sem distinção de tarefas entre eles. Os trabalhadores são relativamente jovens, sendo 16 com idade entre 36 e 45 anos, 10 com menos de 36 anos e 3 com mais de 45 anos. Analisando o tempo de casa, 12 pessoas trabalham na instituição por menos de 10 anos, 15 entre 10 e 20 anos e 2 há mais de 20 anos.

Na Figura 2, é apresentado um fluxograma sobre as principais tarefas desenvolvidas no Serviço de Atendimento administrativo ao público no ambulatório. Durante a recepção dos usuários, as principais tarefas a serem desenvolvidas podem ser divididas em pré e pós-consulta. Antes da consulta, o atendente tem que recepcionar o cliente, confirmar se a consulta foi marcada e pedir-lhe para aguardar sua chamada; depois da consulta, se necessário, agenda-se o retorno.

Ao dar suporte ao médico, as principais tarefas a serem desenvolvidas pelos atendentes são as de disponibilizar o prontuário e responder diretamente a qualquer variação no processo de atendimento (falta de equipamentos, presença de consultas não agendadas, necessidade de consultas de enfermagem, falta de exames, etc.).

Essas tarefas são desenvolvidas continuamente e simultaneamente sem a presença de processos padronizados porque as necessidades variam muito em cada instante, dependendo da chegada de pacientes e das consultas médicas. Esta variabilidade provoca a necessidade da existência de várias outras tarefas que permitem responder e alinhar as situações ao atendimento.

Não podemos considerar o Serviço de Atendimento administrativo como um "produto" que o cliente recebe da organização, esse serviço não teria sentido sem considerar o serviço principal entregado pela organização ao usuário. Com relação aos conceitos trazidos por Normann (1993), o Serviço de Atendimento pode ser definido como um serviço periférico de suporte ao serviço foco de consultas médicas, seu impacto, então, é de suporte para levar o serviço principal ao sucesso, mesmo sendo um serviço periférico, sua importância é muito significativa pr causa do papel de mediador entre clientes e médicos.

\subsection{Características do serviço}

Com base nas características do serviço apresentadas por Bowen e Ford (2002), podem ser identificadas as seguintes características:

- Intangibilidade: o arquivamento e a disponibilização dos prontuários e das informações médicas não são visíveis para o cliente, sua avaliação está focada no bom atendimento, na postura dos trabalhadores nos balcões e na interação com eles. Isso leva os usuários a não terem completo reconhecimento e entendimento da importância de tal serviço e das atividades de retaguarda dos atendentes;

- Perecibilidade: o trabalho dos atendentes apresenta forte interdependência do trabalho dos médicos, especialmente das consultas médicas. O fluxo de operação das consultas depende da disponibilidade dos médicos e da demanda dos pacientes, sendo gerenciado pelo agendamento das consultas a partir da especificação do horário de atendimento dos médicos. Como a oferta desses horários é frequentemente menor do que a demanda dos pacientes, mesmo com horário marcado os pacientes esperam muito tempo; e 
- A análise do processo de agendamento das consultas mostrou que a especificação dos horários de atendimento obedece menos à lógica da organização e segue quase exclusivamente as necessidades dos médicos. Como resultado, o fluxo de pacientes no ambulatório apresenta picos nos horários de meio da manhã e começo da tarde como pode ser visto na Figura 3, que apresenta o número médio (em intervalos de 15 minutos) de consultas agendadas no Ambulatório.

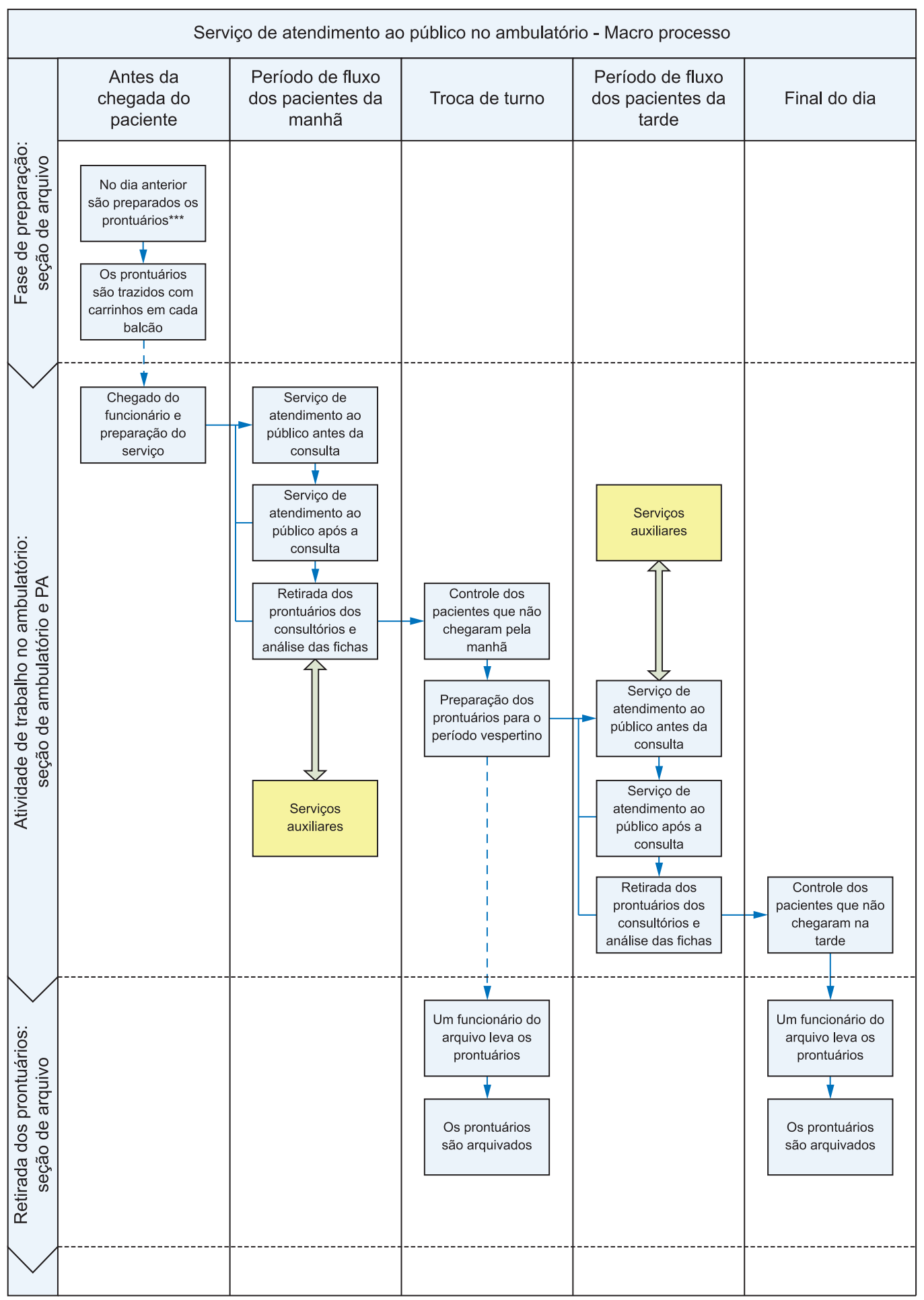

Figura 2. Macroprocesso das atividades dos funcionários da Seção de Ambulatório.*** Existem exceções. 


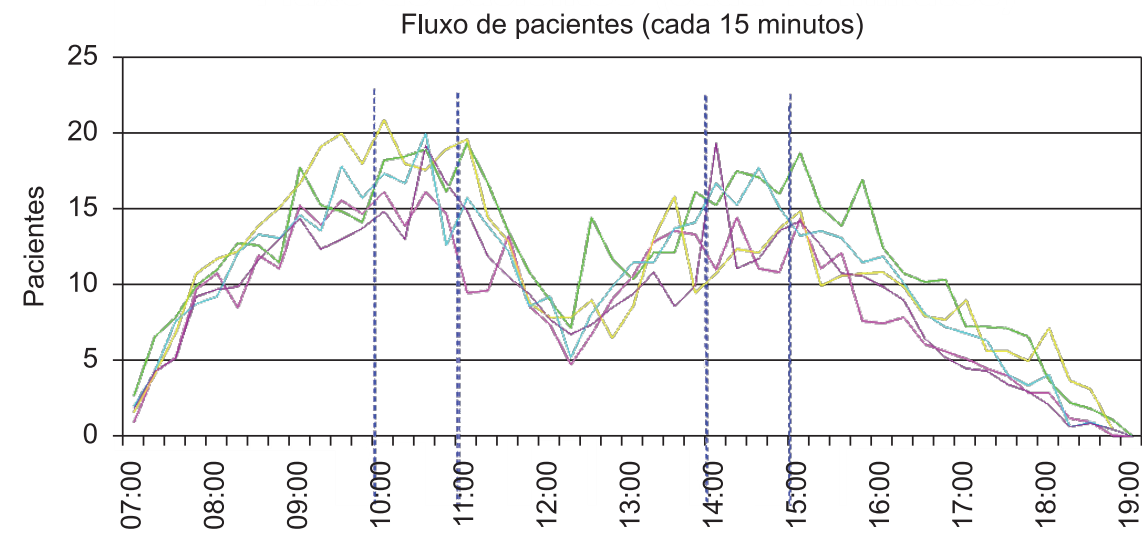

\begin{tabular}{|ll|}
\hline - Segunda-feira & - Terça-feira \\
— Quinta-feira & - Sexta-feira \\
\hline
\end{tabular}

Figura 3. Fluxo médio semanal de pacientes no Ambulatório. Gráfico elaborado a partir de dados coletados durante oito semanas.

As consultas se concentram na metade da manhã (entre $10 \mathrm{~h}$ e $11 \mathrm{~h}$ ), no começo da tarde (entre $14 \mathrm{~h}$ e $15 \mathrm{~h}$ ) e em alguns dias específicos da semana (segundas e quartas-feiras são os dias com a maior média de consultas).

Nos períodos de alto fluxo de clientes, há, portanto, filas de espera nos balcões, baixa organização no ambulatório e um atendimento, por parte dos funcionários, menos personalizado e menos cuidadoso. A saída implantada para o gerenciamento das longas filas foi a instalação de uma televisão em cada lugar de espera. Os efeitos negativos da situação recaem, porém, sobre os atendentes, que têm que enfrentar a insatisfação dos pacientes.

As maiores queixas dos clientes chegam nestes períodos, quando a oferta de serviço é mais próxima da demanda, piorando, então, a qualidade do atendimento e do nível de serviço. Além disso, nem todas as consultas são marcadas, pois existem alguns serviços de pronto atendimento para os casos mais urgentes, que permitem consultas no dia do pedido e dependem do número das necessidades cotidianas chegando ao hospital. Isso cria sobrecarga de trabalho, sobretudo no caso da necessidade requerida por parte do médico de ter disponibilizado o prontuário.

- Coprodução: o Serviço de Atendimento administrativo, sendo desenvolvido em contato direto com o cliente, apresenta também a característica de coprodução. No primeiro contato com os atendentes, os clientes levam o cartão pessoal do hospital com a hora do agendamento marcada ou as fichas, no caso de serviços de pronto atendimento. Na presença da necessidade de se passar em serviços alocados fora do ambulatório, ainda, são os pacientes que levam as fichas de um lugar para o outro. Dentro do ambulatório, este tipo de coprodução é fortemente limitado, por receio de se perder tais informações. É incentivada a coprodução no reagendamento: se necessário o retorno, $\mathrm{o}$ médico entrega ao cliente a possível data de volta (ou apenas indica o possível mês de retorno) com a ideia de que o paciente passe diretamente no balcão de atendimento para a inserção desta informação no sistema de informação do hospital. O reagendamento, então, é ajudado pela coprodução do paciente que, partindo das disponibilidades do médico e discutindo com o atendente, identifica a melhor data de retorno. Neste ponto, cabe ressaltar que, no processo de coprodução em que o médico envia o paciente para o balcão de atendimento, podem acontecer falhas, tais como o cliente não entender que deve passar no balcão, por exemplo. Este mal entendido provoca, no instante do retorno do cliente, grandes problemas relacionais entre o atendente e o paciente, porque o último exige ser atendido, mesmo não estando registrado no sistema de informação hospitalar.

\subsection{Avaliação do serviço}

Por meio das entrevistas livres com alguns clientes sobre índices específicos que podem impactar na percepção de qualidade do serviço, foi observado 
como a avaliação feita pelos pacientes aos funcionários é, muitas vezes, influenciada por aspectos negativos ligados à assistência médica (por exemplo, um alto tempo de espera antes da consulta médica), a aspectos burocráticos (por exemplo, a falta de consultas livres para serem agendadas) e incompreensões ligadas à variabilidade do processo de trabalho (por exemplo, se as informações de localização são dadas rapidamente por que os atendentes são muitos atarefados).

Com base nessas entrevistas preliminares, que permitiram a individuação de oito entre os indicadores de serviço mais relevantes para o cliente, foram introduzidas outras entrevistas estruturadas com o objetivo de entender os KPI de serviço que influenciam sobremaneira na qualidade percebida pelo cliente sobre o Serviço de Atendimento ambulatorial. Foi aplicada a metodologia QPS, para os objetivos do estudo, e não foi necessário dividir e classificar os clientes em grupos homogêneos.

Dos 96 clientes entrevistados, perguntou-se que ordem de importância atribuíam aos 8 indicadores (valor 1 ao mais importante e 8 ao menos importante) e qual a avaliação VIEi singular sobre cada KPI (atribuindo valores com critério "passo constante" entre 1 - péssimo e 4 - ótimo).

A aplicação da metodologia QPS, na Tabela 1, permitiu chegarmos às seguintes constatações:

- Os KPI podem ser divididos em dois grupos bem definidos: os primeiros quatro, mais importantes, e um segundo grupo de outros quatro KPI, menos importantes. O segundo grupo é caracterizado por não ter KPI que envolvam atividades diretas do médico. A análise mostra como a importância atribuída à assistência administrativa do funcionário do SAME é considerada baixa e fica no segundo grupo;

- Os mesmos grupos de importância podem ser utilizados, embora de modo menos marcado, para dividir dois grupos de diferente avaliação da qualidade percebida: aqueles que têm pior qualidade (os considerados mais importantes) e aqueles que têm maior qualidade relativa ao KPI (os considerados menos importantes).
A assistência do funcionário do SAME é considerada como o terceiro KPI com maior pontuação, ficando com uma avaliação um pouco inferior ao "bom"; e

- O valor final de QPI mostra que a performance do hospital é considerada como positiva apesar de um indicativo próximo do negativo. Numa comparação, o resultado do serviço de assistência do funcionário do SAME é melhor, ou seja, significa que o trabalho dos atendentes levanta o valor do QPS na percepção de qualidade de todo o serviço de Ambulatório.

$\mathrm{O}$ resultado final desta análise mostra como a avaliação do trabalho dos atendentes não é independente da avaliação de outros aspectos do serviço de Ambulatório, pois os atendentes recebem queixas de aspectos do serviço de Ambulatório, sem exercer, no entanto, influência sobre eles. Além disso, a qualidade percebida destes aspectos é inferior àquela que é diretamente responsável; fato que provoca desmotivação e senso de injustiça relativa aos outros atores envolvidos no serviço médico ambulatorial, sobretudo com os médicos.

A avaliação da qualidade do Serviço de Atendimento administrativo não é feita apenas pelos pacientes, mas também por meio dos médicos, os quais são os clientes internos. Por meio de uma entrevista estruturada foram levantados os seguintes índices com impacto na qualidade percebida do serviço:

- Número de interrupções nas consultas;

- Rapidez em resolver eventuais atividades fora da rotina; e

- Tempo médio de busca de prontuários para clientes não agendados.

A organização também apresenta alguns índices de avaliação da qualidade do Serviço de Atendimento. Os principais, somados à prestação de um ótimo serviço, são:

- Número de queixas de mau atendimento por parte dos clientes; e

- Número de queixas de mau suporte por parte dos médicos.

Tabela 1. Pesquisa QPS no Ambulatório.

\begin{tabular}{|c|c|c|c|c|c|}
\hline & \multirow{3}{*}{\begin{tabular}{|c|}
$\begin{array}{c}\text { Importância } \\
\text { média }\end{array}$ \\
2,675 \\
\end{tabular}} & \multirow{3}{*}{$\begin{array}{l}\text { VIEi } \\
2,750 \\
\end{array}$} & \multirow{3}{*}{$\begin{array}{c}\text { PIEi } \\
0,178 \\
\end{array}$} & \\
\hline & & & & & \multirow{2}{*}{$\begin{array}{l}\text { QPSi } \\
0,490 \\
\end{array}$} \\
\hline A & Pontualidade na assistência médica & & & & \\
\hline $\mathrm{B}$ & Tempo de espera para uma vaga de retorno & 2,621 & 2,375 & 0,177 & 0,421 \\
\hline $\mathrm{C}$ & Presença de visitas agendáveis & 2,828 & 2,188 & 0,171 & 0,375 \\
\hline $\mathrm{D}$ & Flexibilidade do médico na assistência médica & 3,172 & 2,688 & 0,162 & 0,435 \\
\hline E & Assistência do atendente do SAME & 5,897 & 2,813 & 0,086 & 0,242 \\
\hline $\mathrm{F}$ & Burocracia: cartão e gestão da agenda das visitas & 5,966 & 2,875 & 0,084 & 0,242 \\
\hline G & Presença de informações corretas no ambulatório & 6,207 & 2,813 & 0,078 & 0,218 \\
\hline $\mathrm{H}$ & Espaço físico & 6,724 & 3,563 & 0,063 & 0,225 \\
\hline & & & & & 2,649 \\
\hline
\end{tabular}


Analisando os índices de qualidade percebida pelos médicos e pelos clientes, pode se dizer que estes não são passíveis de serem influenciados só por parte do atendente. Muitas vezes, esses índices estão fora do alcance dos atendentes que, por sua vez, alimentam sentimentos de impotência e frustração sobre as situações de mau atendimento.

Em virtude de serem avaliados pelos clientes por todos esses índices de avaliação da qualidade, existe a necessidade dos atendentes de gerenciar as próprias emoções.

\subsection{Subjetividade no trabalho}

O atendente é o representante da organização e nele os clientes enxergam toda a instituição, por isso, os processos de capacitação estão voltados para o desenvolvimento de postura o mais alinhada possível com os valores de um bom atendimento aos pacientes. Mesmo não sendo uma obrigação, os atendentes procuram manter a simpatia e tentam dar bom encaminhamento a todos os pedidos. Esta postura dos trabalhadores não elimina a possibilidade de, às vezes, acontecerem discussões e conflitos com outros profissionais ou com pacientes, podendo inclusive ser agredidos verbalmente, em situações tipicamente anxiogênicas.

Um aspecto detectado durante as entrevistas é a baixa proteção do atendente em relação ao paciente, em particular perto do balcão da psiquiatria. Para reduzir esta tensão, uma estratégia utilizada, sobretudo em períodos de baixo fluxo, é aquela de aumentar a relação de serviço no atendimento, por um cuidado maior com cada paciente. Assim, esses trabalhadores buscam manter a discrição na sua atividade, para garantir que haja condições para que os atendimentos transcorram bem, buscam fazer a parte que lhes diz respeito, evitando que os conflitos ocorram, seja com os clientes ou com os profissionais da equipe da saúde, principalmente com os médicos. Assim, uma parte significativa de seu trabalho permanece escondida e desconhecida, não sendo passível de avaliações baseadas em indicadores de produtividade. Assim, só aflora aquilo que não conseguem dar conta, quando a situação escapa do seu controle, quando não conseguem dar respostas adequadas às demandas dos pacientes e do corpo clínico. Assim, apenas o seu insucesso aparece, fato que lhes causa muita frustração.

\subsection{Discussão geral}

A análise sobre o conceito de serviço, focalizada no atendimento ambulatorial, possibilita um melhor entendimento sobre os problemas enfrentados pelos trabalhadores e as dificuldades existentes para que seja garantida a qualidade. Fica evidente que o problema não se situa exclusivamente no SAME, e que qualquer análise sobre os processos de atendimento deve considerar as diferentes etapas que o compõem.

Desse modo, a qualidade não pode ser avaliada independentemente, deve-se considerar tudo aquilo que está ao redor dela (FERREIRA, 1999). Analisar a importância desta etapa para ajudar a estruturar o serviço de consultas médicas permite identificar o papel dos atendentes e de outros atores que influenciam seu trabalho. Fica evidente que, com relação aos constrangimentos desta tarefa, o papel dos pacientes e dos profissionais de saúde, sobretudo dos médicos, é fundamental, pois eles trabalham como um elo, servindo a racionalidades bem distintas. A referência ao modelo proposto por Kingman-Brundage, George e Bowen (1995) ajuda na análise e na busca de soluções.

A qualidade percebida pelo paciente (racionalidade do cliente) não depende apenas de uma parte do processo, todavia o acolhimento recebido, isto é, a relação de serviço constituída com o atendente do SAME é fundamental, pois se trata não apenas do primeiro contato, o impacto inicial, mas também dos encaminhamentos, tanto antes como depois da consulta médica, propriamente dita.

Outro aspecto importante é a qualidade da atividade de atendimento que produz as condições para que a sequência do atendimento seja mais fluida, com melhor percepção da qualidade.

Dessa forma, os momentos de encontro são vários e com atores diferentes, com vários momentos críticos, em que diferentes racionalidades se confrontam.

Conforme discutido anteriormente, a posição do atendente é a mais delicada, uma vez que ele é o elo entre o paciente e os profissionais de saúde, assim está sujeito a pressões divergentes, e é ele que precisa resolver diferentes problemas do processo. Em seu discurso, há uma aparente aceitação deste fato, todavia, isto é fonte de sofrimento patogênico, uma vez que ele não tem condições para resolver muitos dos problemas, sofrendo diferentes tipos de agressões.

Como explicado no item de avaliação do serviço, existem muitas questões que são atribuídas à responsabilidade dos atendentes quando, na verdade, não o são. O exemplo mais comum é a pressão do usuário sobre os atendentes quando está na espera para entrar em uma consulta médica, sobretudo se a demora for percebida como excessiva. $\mathrm{O}$ atendente, neste caso, só pode tentar acalmar o paciente, mas nada pode fazer para resolver este problema. A atividade de outros atores, como a dos médicos, tem influência significativa na gênese desses problemas, as melhorias nos processos devem considerar esses aspectos também, pois buscar uma resolução apenas no âmbito da atuação dos atendentes seria inconsistente e ineficaz.

Como exemplo da inter-relação e de como os processos são imbricados, é o aparecimento de 
pacientes cujas consultas não foram agendadas. Neste caso, há uma urgência para se encontrar o prontuário, para reduzir o tempo de espera dos clientes e para dar vazão aos desejos dos médicos de cumprir seus objetivos de horário e quantidade de consultas. Considerando que esta busca de prontuários é feita fora da rotina de trabalho dos atendentes e, por natureza, leva tempo, trata-se de uma fonte de variabilidade, de um tipo de evento que invariavelmente ocorre em serviços de saúde. Assim, as tensões entre os diferentes atores ficam mais agudas.

Estas tensões podem ser gerenciadas e diminuídas com o aumento da cooperação entre os atores, mas necessita melhor planejamento das ações por parte da organização, tanto no que diz respeito aos processos internos de atendimento, como naqueles que podem estar voltados para a comunidade adstrita ao hospital. As relações de poder entre os diferentes profissionais interferem nas condições de trabalho dos atendentes. O processo está bastante centralizado na ação do corpo médico, fato que caracteriza a estrutura organizacional como uma Burocracia Profissional, na qual a autoridade é de natureza profissional e é segurada por meio dos conhecimentos especializados (MINTZBERG, 2003).

Assim, cabe aos diferentes atores, em conjunto com os responsáveis pelas operações, em nível local e na comunidade, buscarem maneiras de modificar alguns processos para facilitar o trabalho de todos e para atingir níveis de serviços mais efetivos, com melhor qualidade percebida. A busca de melhorias nos processos pode ser fonte para redução dos conflitos internos, principalmente por que, ao estarem em posição de menor força, os atendentes são os que mais apresentam as consequências do sofrimento patogênico, isto é, com a incidência de doenças, tais como os distúrbios psíquicos.

A análise ergonômica anterior, realizada por Bolis (2011), mostrou vários aspectos que poderiam ter influência no trabalho dos atendentes, como o arranjo físico, a qualidade dos equipamentos de informação e os equipamentos para armazenagem dos prontuários. Nesta pesquisa, ficaram evidentes aspectos ligados à relação de serviço, às relações entre os profissionais do hospital e à organização dos processos, que deveriam ser modificados também no sentido de melhorar a situação dos atendentes.

As questões levantadas por parte dos atendentes, neste trabalho, foram dirigidas sobre os balcões de atendimento, que são amplos demais, não são cômodos, não permitem trabalhar em segurança, não são funcionais e induzem a adoção de posturas corporais desconfortáveis, propiciando o aparecimento de doenças por esforços repetitivos. Outras questões estão ligadas à perspectiva de informatização dos prontuários e de todo processo de atendimento, o que trará uma reconfiguração de todo o processo de prestação de serviço, podendo ter efeito positivo sobre a saúde dos funcionários do atendimento e sobre a produtividade do serviço.

Um último aspecto a ser considerado, que influencia no mal-estar dos funcionários de assistência ambulatorial, decorre do fato de que há uma forte flutuação da demanda, que dificilmente é coberta pela oferta dos serviços, uma vez que esses são perecíveis, não são estocados e, sobretudo, dependem do contato direto entre os trabalhadores e os clientes. Em outros contextos, distintos do hospital, é possível prever a flutuação da demanda com a possibilidade de gerenciá-la pela gestão da capacidade (CAON; CORRÊA, 2002). Isso não é possível no caso em estudo: a oferta de consultas médicas é fixa e determinada pelo número de médicos contratados pela instituição, que é minimizado, tendo em vista a estratégia da organização de ser mais escola do que um hospital, atendendo às necessidades da comunidade local, logo, enquanto a demanda atendida é nivelada, a oferta permanece fixa, mesmo se a demanda real é bem maior.

\section{Conclusão}

$\mathrm{O}$ artigo permitiu o desenvolvimento, partindo do conceito de serviço, de maior entendimento sobre a atividade de atendimento ambulatorial, por meio da análise e avaliação dos elementos que o constituem, além de possibilitar ao autor entendimento das origens das queixas por parte dos atendentes.

O serviço foi analisado, sobretudo em relação à posição de fronteira do trabalho do atendente no confronto de profissionais da saúde e pacientes, foi confirmada a presença de fortes pressões, sendo que os maiores problemas sentidos pelos atendentes aparecem quando eles desempenham um trabalho de mediador entre diferentes racionalidades. Se a organização e a gestão do trabalho fossem transformadas, no sentido de aumentar a cooperação entre os diferentes trabalhadores do hospital, e se houvesse desenvolvimento de ações que envolvessem a população adstrita, para aprimorar o uso dos recursos do sistema de saúde, poderia haver consequências positivas para a saúde dos trabalhadores no atendimento e para a qualidade do serviço.

$\mathrm{O}$ fato de haver problemas de saúde nos trabalhadores de uma instituição como um hospital universitário pode servir de alerta para ajudar na organização e no planejamento de seus serviços. Além de trazer benefícios, no que diz respeito à saúde dos trabalhadores, estas mudanças, cuja finalidade seria tornar os serviços mais eficientes e eficazes, podem aumentar a qualidade percebida por parte dos clientes.

A metodologia de análise permitiu o levantamento das informações necessárias, entretanto houve dificuldade para acessar os profissionais de saúde, principalmente os médicos, para que se conhecesse seu ponto de vista com relação aos processos e sobre 
a responsabilidade do SAME, parte dos processos de atendimento aos pacientes no ambulatório e no pronto atendimento.

Em pesquisas futuras serão abordados métodos e ferramentas que poderão ser utilizados pela organização para minimizar o problema levantado por parte dos atendentes. Um foco particular será dado à discussão da implementação de um comitê de melhoria na organização.

\section{Referências}

ABRAHÃO, J. et al. Introdução à ergonomia da prática à teoria. São Paulo: Blucher, 2009.

BITNER, M. J. Building service relationships: it's all about promises. Journal of Academy of Marketing Science, v. 23, n. 4, 1995. http://dx.doi. org/10.1177/009207039502300403

BOLIS, I. Análise Ergonômica em ambiente hospitalar: estudo de caso em um hospital universitário. In: ENCONTRO NACIONAL DE ENGENHARIA DE PRODUÇÃO, 31., 2011, Belo Horizonte. Anais... ABEPRO, 2011.

BOWEN, J.; FORD, R. C. Managing Service Organizations: does having a "thing" make a difference? Journal of Management, v. 28, n. 3, 2002.

CAON, M., CORRÊA, H. Gestão de Serviços: lucratividade por meio de operações e de satisfação dos clientes. São Paulo: Atlas, 2002.

CARLZON, J. A hora da verdade. 10. ed. Rio de Janeiro: COP, 1994. 120 p.

CHAPANIS, A. Engenharia e o relacionamento homemmáquina. São Paulo: Atlas, 1997.

DEJOURS, C. Addendum: da psicopatologia à psicodinâmica do trabalho. In: LANCMAN, S.; SZNELWAR, L. I. (Orgs.). Christophe Dejours: da psicopatologia à psicodinâmica do trabalho. Rio de Janeiro: Ed. Fiocruz; Brasília: Paralelo 15, 2004.

DEJOURS, C. Trabalho, tecnologia e organização: A avaliação do trabalho submetida à prova do real. São Paulo: Blucher, 2008.

FALZON, P. Ergonomia. São Paulo: Edgard Blucher, 2007.

FERREIRA, M. C. Serviço de Atendimento ao público: O que é? Como analisá-lo? Esboço uma abordagem teóricometodológica em Ergonomia. Brasília: Laboratório de Ergonomia, Universidade de Brasília, 1999.

GADREY, J. Emprego, produtividade e avaliação do desempenho em serviços. In: SALERNO, M. S. (Org.). Relação de serviço, Produção e avaliação. São Paulo: SENAC, 2001.

GIANESI, I. G. N. Administração estratégica de serviços. São Paulo: Atlas, 1994.

GRONROOS, C. A service quality model and its marketing implications. European Journal of Marketing. v. 18, n. 4, 1984. http://dx.doi.org/10.1108/ EUM0000000004784
GRONROOS, C. Management e marketing dei servizi. Torino: ISEDI, 1994.

GUÉRIN, F. et al. Compreender o trabalho para transformá-lo: a prática da ergonomia. São Paulo: Edgard Blücher, 2001.

HARTLINE, M. D.; JONES, K. C. Employee performance cues in a hotel service environment: influence on perceived service quality, value, and word-of-mouth intentions. Journal of Business Research, v. 35, 1996.

HESKETT, J. L.; SASSER, W. E.; HART, C. W. L. Serviços revolucionários: mudando as regras do jogo competitivo na prestação de serviços. São Paulo: Pioneira, 1994.

HOCHSCHILD, A. The Managed Heart. Berkeley: University of California Press, 1983.

HUBAULT, F. La relation de service, opportunités et questions nouvelles pour l'érgonomie. Paris: Octares Editions, 2001.

KINGMAN-BRUNDAGE, J.; GEORGE, W. R.; BOWEN, D. E. Service Logic: achieving service system integration. International Journal of Service Industry Management, v. 6, n. 4, 1995. http://dx.doi. org/10.1108/09564239510096885

MINTZBERG, H. Criando organizações eficazes. São Paulo: Atlas, 2003.

MONTMOLLIN, M. L'intelligence de la tâche: élements d' ergonomie cognitive. Berne: Peter Levy, 1984.

NORMANN, R. Administração de Serviços. São Paulo: Atlas, 1993.

RUGGERI, R. Elementi di logistica industriale. Milano: Ed. CUSL, 1999.

SALERNO, M. S. A seu serviço: interrogações sobre o conceito, os modelos de produção e o trabalho em atividades de serviços. In: SALERNO, M. S. (Org.). Relação de serviço, Produção e avaliação. SENAC, 2001.

SEBRAE. Metodologia. Implementação da qualidade. Satisfação dos Clientes - Régua e Compasso. Brasília: Banco do Brasil, 1995. v. 3.

SHOSTACK, G. L. Planning the services encounter. In: CZEPIEL, J.; SOLOMON, M.; SURPRENANT, C. The service encounter. Lexington: Lexington Books, 1985.

SILVA, M. T.; TAVARES, J. C. Táticas Utilizadas Por Trabalhadores de Contato-Cliente. Revista Relações Humanas, v. 15, set. 1998.

VAN MAANEN, J. The smile factory. In: FROST, P. et al. (Eds.). Reframing Organizational Culture. Newbury Park: Sage Publications, 1991. p. 58-76.

WEATHERLY, K.; TANSIK, D. Tactics used by customer-contact workers: effects of role stress, boundary spanning and control. Tucson: University of Arizona, 1993.

WISNER, A. Questões epistemológicas em ergonomia e em analise do trabalho. In: DANIELLOU, F. A ergonomia em busca de seus princípios: debates epistemológicos. São Paulo: Edgar Blutcher, 2004.

ZEITHAML, V. et al. Delivering Quality Service. New York: The Free Press, 1990. 